\title{
Pharmacokinetics of Ethinyloestradiol in Rabbits After Intravenous Administration
}

\author{
N. Fernández, M. Sierra, M.J. Diez, T. Terán, A.M. Sahagún, and J.J. García
}

The pharmacokinetics of ethinyloestradiol ( $E E_{2}$ ) after intravenous administration of 30,50 and $100 \mu \mathrm{g} \cdot \mathrm{kg}^{-1}$ was investigated in rabbits. A high-performance liquid chromatographic (HPLC) method with electrochemical (EC) detection was used to measure $E E_{2}$ in plasma samples in order to avoid the interferences of natural oestrogens.

After compartmental analysis, the disposition of $E E_{2}$ was well described by a two-compartmental open model with mean values of: $\alpha=0.3448 \pm 0.2922,0.1965 \pm 0.1755,0.3058$ $\pm 0.1225 \mathrm{~min}^{-1}$, and $\beta=0.0137 \pm 0.0018,0.0140 \pm 0.0065$, $0.0198 \pm 0.0066 \mathrm{~min}^{-1}$, for the three doses studied, respec tively.

There were no dose-related differences (ANOVA, $P<$ 0.05 in $a, b$ or $V_{s s}$, but significant differences were detected in clearance $(90.9 \pm 18.7 ; 80.6 \pm 17.6 ; 116.3 \pm 21.5$ ml. $\mathrm{min}^{-1} . \mathrm{kg}^{-1}$ ) between the $100 \mathrm{\mu g} \cdot \mathrm{kg}^{-1}$ group and lower dose groups. The AUC increased significantly with the doses $(341.7 \pm 67.1 ; 645 ; 8 \% \pm 143.9 ; 892.2 \pm 211.9$ ng.min. $\left.\mathrm{ml}^{-1}\right)$. After non-compartmental analysis there were no significant differences in $\lambda, M R T$ or $V_{s s}$ as a function of dose, but these differences were significant when $\mathrm{Cl}$. or AUC were compared. There were tro significant differences in AUC or Cl values obtained by compartmental and non-compartmental analysis. CONTRACEPTION 1996; $53: 307-312$

KEY WORDS: ethinyloestradiol; pharmacokinetics, intravenous administration, rabbits, oestrogens

\section{Introduction}

$\mathrm{E}$ thinyloestradiol is a synthetic oestrogen widely used as the oestrogenic component in oral contraceptives, in the treatment of menopausal

Departrient of Physiology. Pharmacology and Toxicology. Facuity of Veterinary. University of Leon Campus Vegazana $s / n$. León 24071. Spa!n

Name and acdress for correspondence: Dr. Neliga Femández Martinez. De- partment of Physioiogy. Pharmacology and Toxicoiogy. Faculty of Veterinary. Universty of Leor: Campus Vegazana s/n. Leor. 24071. Spart. Tel. 34-8729: 25:4: Fax. 34-8?-20?:94

Submitted for Dublicazion October 30. 1995

Revised jan:uary 16. 1996

A.ccepted ior pubticator. February 13. 1996 symptoms, functional uterine bleeding, for the inhibition of lactation and also for palliative treatment of breast cancer in postmenopausal women and prostate cancer ${ }^{1,2}$ Its usefulness appears to result from its slow elimination relative to $17 \beta$-oestradial.

Goldzieher indicated in $1994^{3}$ that, although the pharmacokinetics of $\mathrm{EE}_{2}$ has been studied intensively for more than a decade. Very seldom, however, has there been a complete pharmacokinetic analysis of the data. Moreover, there appears to be a wide variation in the values for some of the pharmacokinetic parameters as well as no explanation of how these parameters were calculated. Methodologic problems limit the reliability of pharmacokinetic analyses and additionally, investigators persist on using conventional contraceptive doses ( 30 to $35 \mu \mathrm{g}$ ) for their pharmacokinetic studies, thus straining the limits of detectability of the available analytical methods. ${ }^{3}$

Radioimmunoassay (RIA) is the most widely used. method to measure very low levels of $\mathrm{EE}_{2}$, but it shows cross-reactivity with several natural oestrogens $^{4,5}$ and the concurrent administration of 19 norprogestins has also raised considerable problems of specificity when they have a $17 \alpha$-ethinyl side chain. On the other hand, blank values may be within the range of $\mathrm{EE}_{2}$ levels in the later stages of the elimination phases. ${ }^{3}$ Goldzieher also indicates that nonspecific plasma blanks create a problem that is often not adequately solved; substraction of an average blank derived from a plasma pool is unreliable due to variation of the blank from cycle day. ${ }^{6}$

In order to solve these problems, a HPLC method with EC detection has been developed to determine $\mathrm{EE}_{2}$ in rabbit plasma. ${ }^{7}$ The procedure can detect as little as $50 \mathrm{pg} \cdot \mathrm{ml}^{-1}$ and it is highly reproducible.

The purpose of the present study was to establish the compartmental and non-compartmental pharmacokinetic parameters for $\mathrm{EE}_{2}$ in rabbits after intravenous administration and determine whether or not they are dose-dependent. 


\section{Materials and Methods}

Siudy Desigr:

Experiments were carried out on 18 healthy female New Zealand white rabbits with a body weight range of $2.5-3.1 \mathrm{~kg}$. Rabbits were housed in individual cages with environmentally controlled conditions $i t \in m$. perature was inaintained at $19=2^{\circ} \mathrm{C}$ and $12 \mathrm{~h}$ light -12 h lark eyclel for at least 1 wcek before use. These animals had free access to standard laboratory chow and water.

The rabbits were surgically fitted with a sampling cannula in the left carotid artery using Silastic medical-grade tubing (1.02 $\mathrm{mm}$ ID $\times 2.16 \mathrm{~mm}$ OD) under anaesthesia with sodium pentobarbital (Barcia, Madnd, Spain I, $30 \mathrm{mg} . \mathrm{kg}^{-1}$, i.v. These cannulae were flaced before the trial started.

The rabbits were randomly divided into three groups which received 30,50 and $100 \mu \mathrm{g} \cdot \mathrm{kg}^{-1}$ of $\mathrm{EE}_{2}$ (Sigma, St. Louis, MO, USA), respectively. EE, was administered intravenously as a solution in a mixture of saline:ethanol $(4: 1, \mathrm{v} / \mathrm{v})$ into the marginal ear vein. Hepirinized blood samples $(3 \mathrm{ml})$ were collected from the left carotid artery before and at $3,5,10,15,20,25$, $30,60,90,120,150,180,210,240,360,480,720$ and 1440 minutes after $E E_{2}$ administration. Plasma was immediately separated and frozen at $-20^{\circ} \mathrm{C}$ until analysed. $E E_{2}$ in plasma was quantitated by HPLC-EC detection. The method is highly specific for $E_{2}$ without cross-reactivity to other cestrogens. Neither heparin nor pentobarbital had any effect on the assay.

\section{Pharmacokinetic Studies}

Pharmacokinetic analysis was performed based on a compartmental as ivell as on a non-compartmental description of the data observed. The pharmacokinetic model best describing the plasma concentrationtime courses of $\mathrm{EE}_{2}$ was determined using the PC. NONLIN computer program (Statistical Consultants, Lexington, $\left.\mathrm{KY}\right|^{8}$ with reciprocal concentration weights $11 / C$ !. Initial estimates of the parameters were determined by TANA."

The best pharmacokinetic model jone, two and three compartments) was determined by application of Akaike's information criterion ${ }^{10}$ and graphical analysis of :weighted residuals. A two-compartment open model was selected and the equation used to describe $\mathrm{EE}_{2}$ pharmacokinetics was:

$C=A e^{-\alpha 2}+B e^{-B i}$

where $\alpha$ and $\beta$ are the distribution and elimination rate constants, and $A$ and $B$ are their respective zero time intercepts. The other compartmental parameters were calculated by standard methods. ${ }^{11}$
Thë model independent pharmacokinetic param. eters were calculated using expressions based on sta. tistical moments theor ${ }^{12}$ and on formulae described by Gibaldi and Perrier. "The plasma elimination rate constant $(\lambda)$ was calculated by least squares regression of the logarithm of plasma concentration versus time curve over the terminal elimination phase.

The area under the plasma concentration-time curve from time zero to the last determined sampic time $\left(\mathrm{AUC}_{0-1}\right)$ was calculated by the trapezoidal rule, and the total area under the plasma concentrationtime curve $(A U C)$ by adding $A U C_{0-t}$ to the residual area $\mathrm{AUC}_{\mathrm{r}-x}$ (calculated from $\mathrm{C}_{\mathrm{t}}$, the last experimental plasma concentration, divided by the terminal slope, $\lambda l$. The area under the first moment curve from time zero to time infinity (AUMC) was calculated using the linear trapezoidal rule with extrapolation to infinity. The mean residence time (MRT) was deter. mined by:

\section{MRT $=$ AUMC $/$ AUC}

The total body clearance $(\mathrm{Cl})$ was calculated by dividing the dose (D) by AUC. The terminal volume of distribution $\left(V_{2}\right)$ was calculated from the ratio of the total body clearance $(\mathrm{Cl})$ and the terminal slope $\{\beta \mid$. The volume of distribution at steady state $i V_{s s}$ : was determined by the equation:

$\mathrm{V}_{\mathrm{ss}}=\mathrm{MRT} \times$ Dose AUC

\section{Statistical Evaluation}

All pharmacokinetic parameters were calculated for each animal and the data presented as arithmetic mean $=$ standard deviation imean $=$ SD . The data obtained from the three treatments were compared for statistical significance by using the one-way and twoway analysis of variance (ANOVA). When the results were significant, the Duncan test was used to evalu. ate differences between data sets and a $P \leq 0.05$ was taken as the level of significance for all analyses.

\section{Results}

Mean and individual plasma concentrations of $E_{2}$ as a function of time following intravenous administra. tion of 30,50 and $100 \mu \mathrm{gg} \mathrm{kg}^{-1}$ to rabbits are shown in Figures 1, 2 and 3, respectively. They show that plasma $E_{2}$ concentrations after each jose declined rapidly in a biexponential fashion with a rapid early $\alpha$ phase (ranging from 0.1965 to $0.3448 \mathrm{~min}^{-1}$ ) and $\mathrm{d}$ terminal $\beta$ phase 10 -fold lower (ranging from 0.0137 to $0.0198 \mathrm{~min}^{-1}$.

The pharmacokinetic parameters obtained by the compartmental analysis of these concentration-time data are summarized in Table 1. The AUC of $E E_{2}$ 


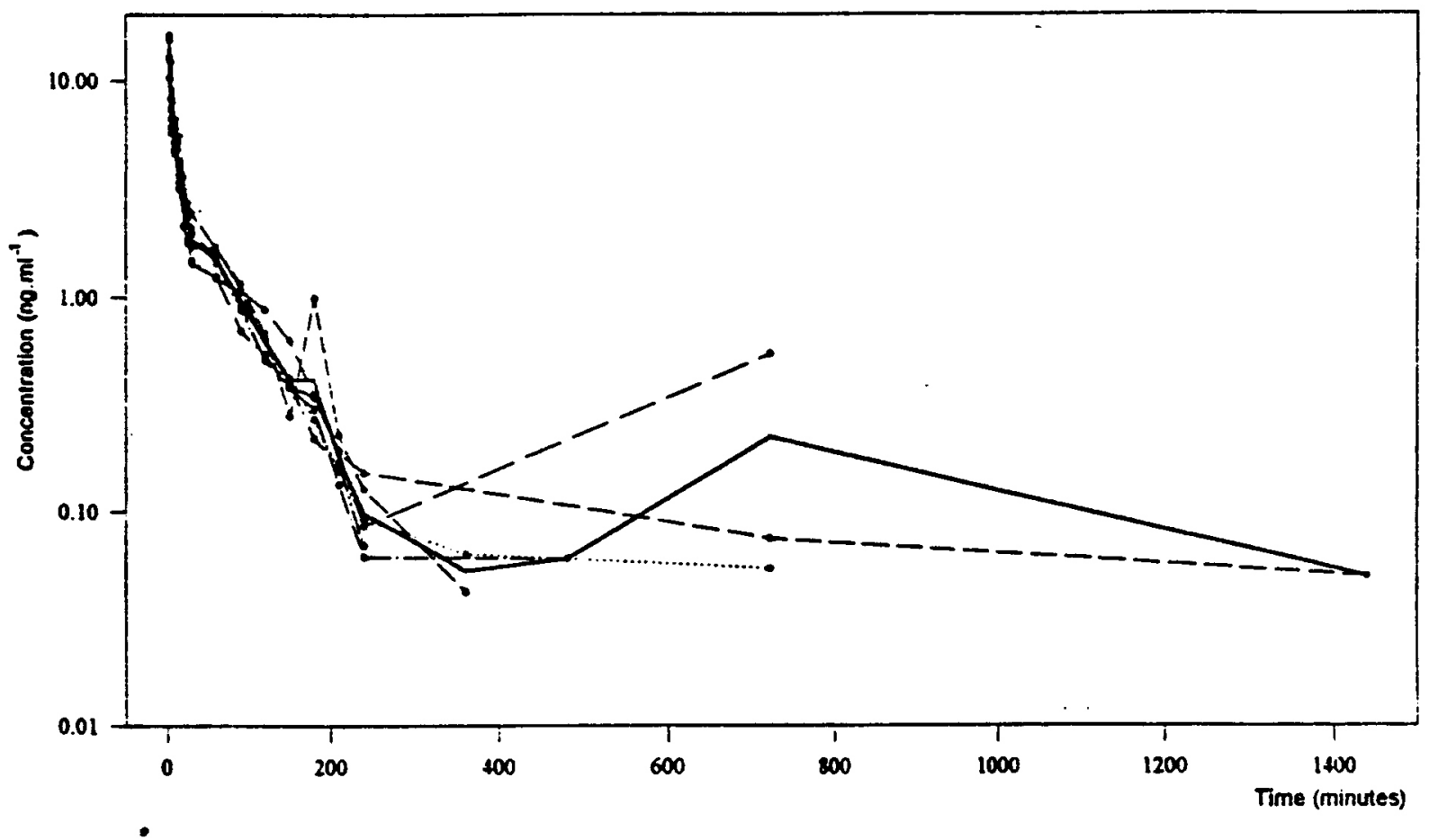

Figure 1. Individual and mean - plasma concentrations of $\mathrm{EE}_{2}$ in rabbits atter intravenous administration of $30 \mathrm{ug} \cdot \mathrm{kg}^{-1}$.

increased significanty with dose. The clearance values were similar $\left\{90.9,30.6\right.$ and $\left.116.3 \mathrm{ml} . \mathrm{min}^{-1} . \mathrm{kg}^{-1}\right\}$ but signiticant differences were detected in this pa. rameter between the 100 ug. $\mathrm{kg}^{-1}$ i.v. group and lower dose groups. The steady-state volume of distribution ranged trom 4.4 to $7.21 . \mathrm{kg}^{-1}$. No significant differences were found when the compartmental param. eters $\alpha, \beta$ and $V_{s s}$ were compared.
The pharmacokinetic parameters derived from noncompartmental analysis are shown in Table 2. There were no significant differences in $\lambda$, MRT, $V_{s s}$ or $V_{a}$ for the three doses studied. The AUC of $\mathrm{EE}_{2}$ increased with dose, while $\mathrm{Cl}$ values were found to be statistically difterent between the 50 and 100 ug. $\mathrm{kg}^{-1}$ groups. Finally, there were significant differences between the values obtained using the compartmental and

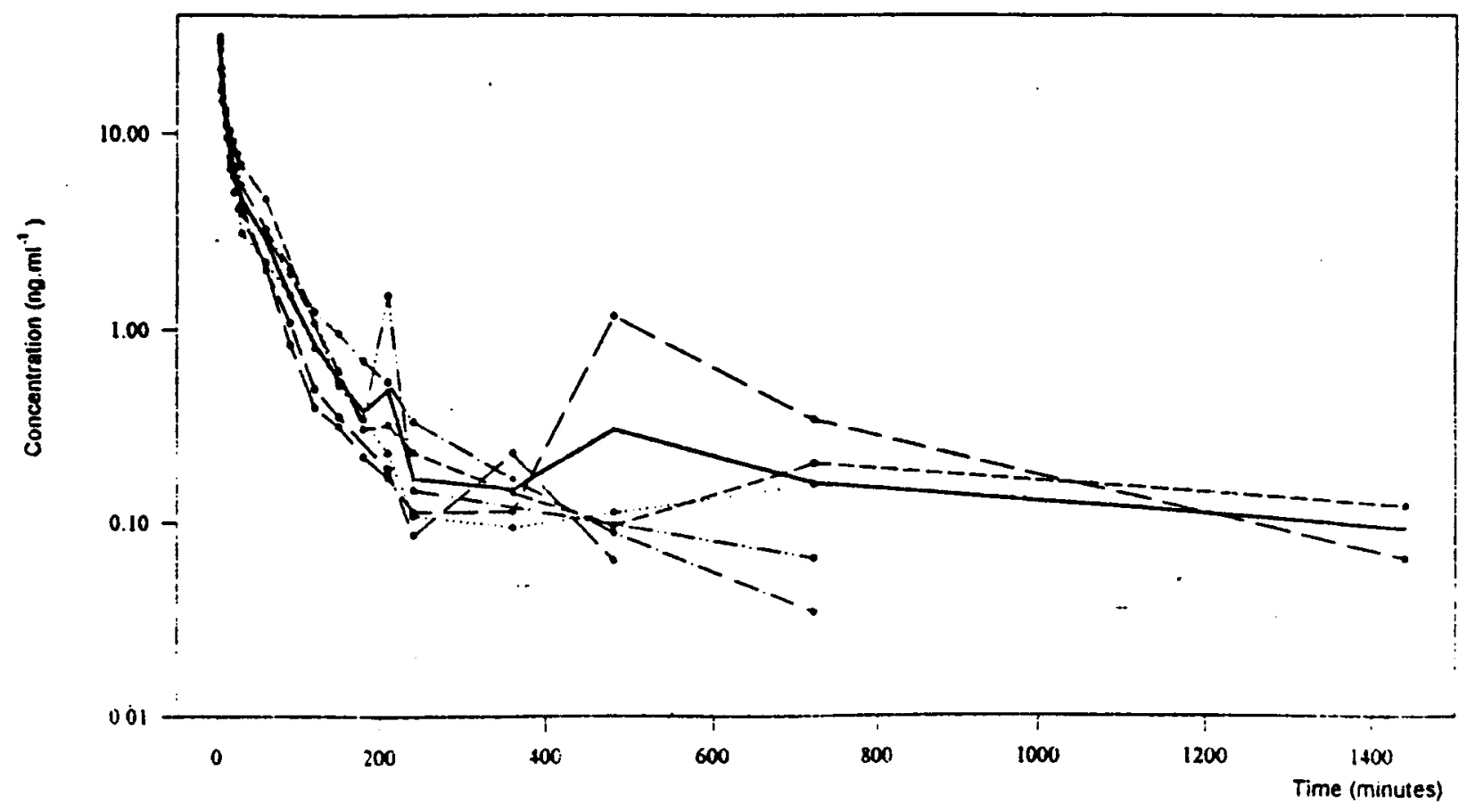

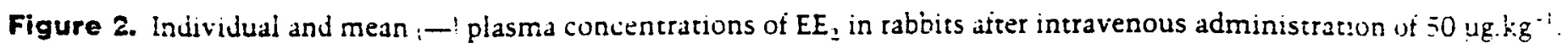




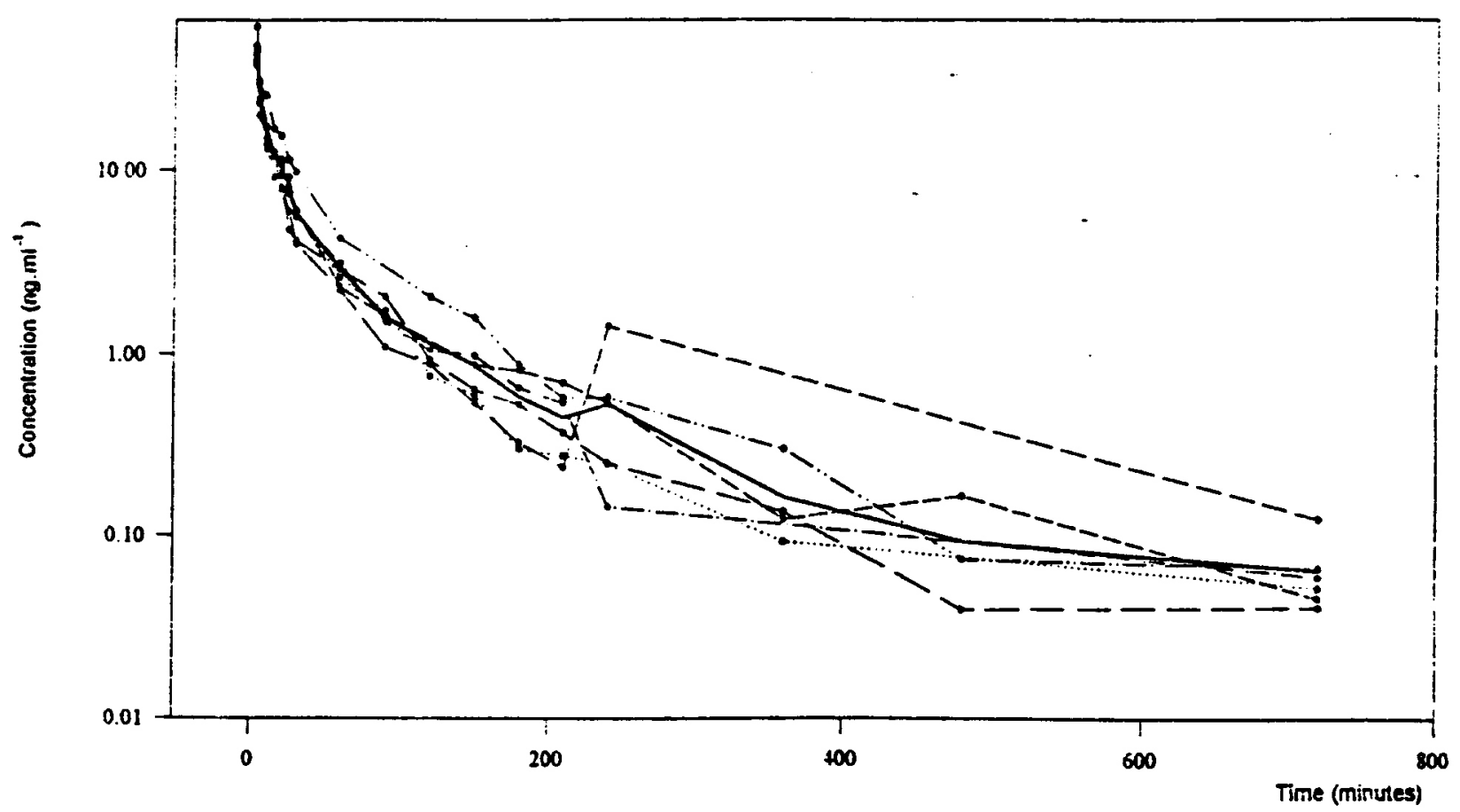

Figure 3. Individual and mean $1-i$ plasma concentrations of $\mathrm{EE}_{2}$ in rabbits after intravenous administration of 100 ug. $\mathrm{kg}^{-1}$.

non-comparmental analysis when $\lambda / \beta, V_{\text {is }}$ and $V_{2}$ were compared while, with the same analysis. AUC and $\mathrm{Cl}$ showed no significant statistical changes.

\section{Discussion}

The model ised by other authors to describe $\mathrm{EE}_{2}$ pharmacokinetics is, in practically all cases, a two- compartmental open model,,$^{3.13-15}$ as in this study. Biphasic decline of $\mathrm{EE}_{2}$ following i.v. administration with the later occurrence of a secondary peak due to enterohepatic circulation, has been previously described in several animal species ${ }^{14}$ as well as in women. ${ }^{10-i}$ s This latter situation is not dear in the present study, in spite of the presence of secondary

Table 1. Pharmacokinetic parameters obtained by compartmental analysis in rabbits after intravenous administratiın of ethinyloestradiol ${ }^{2}$

\begin{tabular}{|c|c|c|c|}
\hline \multirow[b]{2}{*}{ Parameters } & \multicolumn{3}{|c|}{ Dose (ug.kg $\left.{ }^{-1}\right)$} \\
\hline & 30 & 50 & 100 \\
\hline 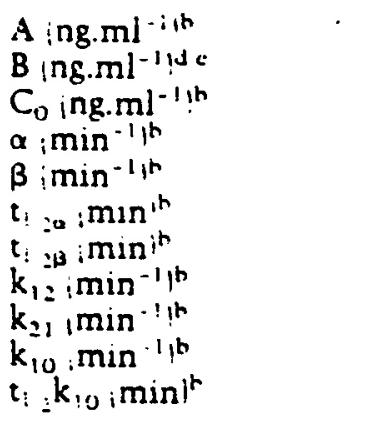 & $\begin{aligned} 43.36 & =33.93 \\
3.22 & =0.87 \\
46.58 & =34.63 \\
0.3448 & =0.2922 \\
0.0137 & =0.0018 \\
3.28 & =1.31 \\
51.09 & =5.94 \\
0.1968 & =0.1866 \\
0.0379 & =0.0054 \\
0.1239 & =0.1030 \\
3.96 & =4.38\end{aligned}$ & $\begin{aligned} 37.45 & =28.97 \\
6.63 & =4.26 \\
+4.08 & =32.31 \\
0.1965 & =0.1755 \\
0.0140 & =0.0065 \\
5.34 & =2.99 \\
116.78 & =181.78 \\
0.1044 & =0.1238 \\
0.0417 & =0.0266 \\
0.0645 & =0.0337 \\
12.67 & =4.58\end{aligned}$ & $\begin{aligned} 78.47 & =25.72 \\
12.28 & =5.51 \\
90.75 & =30.09 \\
0.3058 & =0.1225 \\
0.0198 & =0.006 .6 \\
2.92 & =2.11 \\
39.95 & =18.72 \\
0.1620 & =0.0731 \\
0.0590 & =0.0245 \\
0.1045 & =0.0384 \\
7.54 & =3.17\end{aligned}$ \\
\hline 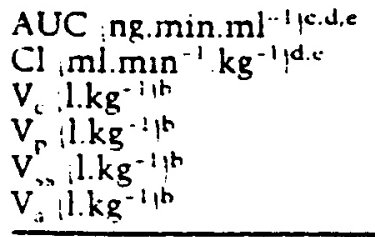 & $\begin{aligned} 3+1.65 & =67.14 \\
90.86 & =18.71 \\
1.25 & =0.80 \\
3.51 & =0.80 \\
4.76 & =1.48 \\
6.78 & =1.98\end{aligned}$ & $\begin{aligned} 645.76 & =143.87 \\
80.64 & =17.60 \\
1.52 & =0.71 \\
5.68 & =8.54 \\
7.21 & =8.80 \\
13.76 & =21.63\end{aligned}$ & $\begin{aligned} 892.17 & =211.93 \\
116.29 & \pm 21.52 \\
1.24 & \pm 0.51 \\
3.20 & =0.94 \\
4.44 & =1.40 \\
6.61 & =3.08\end{aligned}$ \\
\hline
\end{tabular}

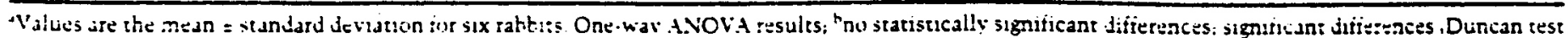
$P \because 00=$ heeween -30 and 50 ug $\mathrm{kg}^{-1},{ }^{1} 30$ and $100: 12 \mathrm{~kg}^{-1}$ - 50 and 100 ug. $\mathrm{kg}^{-1}$. 
Table 2. Pharmacokinetic parameters obtained by non-compartmental analysis in rabbits after intravenous administration of ethinyloestradiol ${ }^{2}$

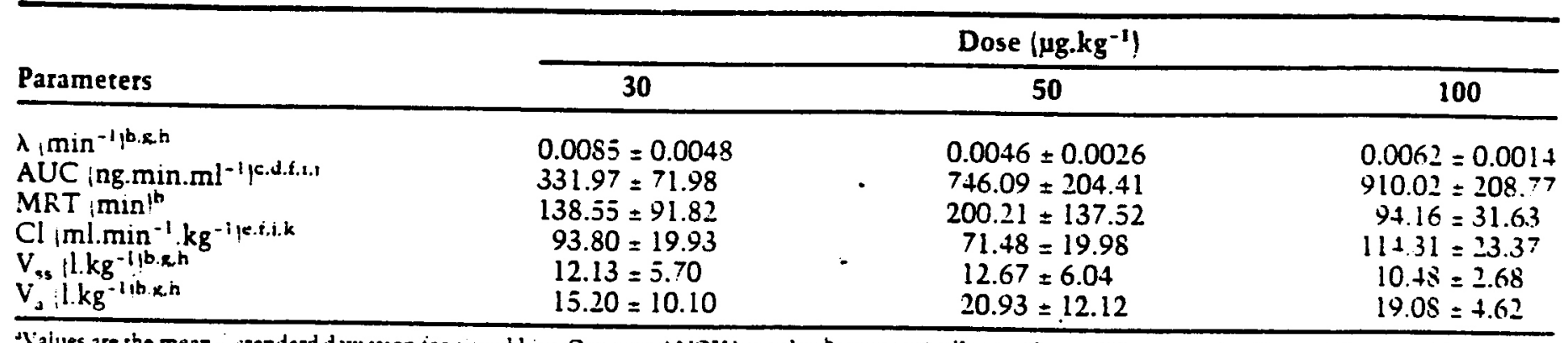

Walues are the mean = standard deviation tor sux tabbits. One-wav ANOYA results: bo statistically stgnificant differences: signincant ditierences Duncan tes:

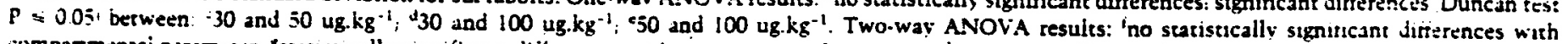

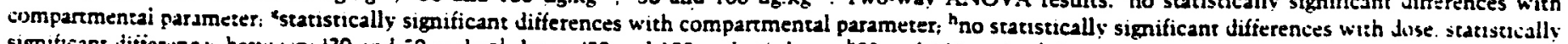

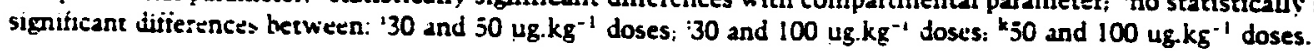

peaks in the mean plasma curves (Figures 1,2 and 31. In the 30 and 50 ug. $\mathrm{kg}^{-1}$ dose curves, these peaks are caused by two animals, while in the 100 ug. $\mathrm{kg}^{-1}$ dose curve, the peak is produced by one animal. As no plasma peaks are present in 13 of the 18 animals, it is cleat that a possible enterohepatic circulation would have a limited quantitative importance in the pharmacukinetics of $E E_{2}$ atter $i . v$. administration in rabbits.

The high values obtained for the different volumes of distribution indicate a large distribution of the drug. The significant differences tound in clearance do not allow us to say that pharmacokinetics of $E E_{2}$ is linear over the $30-100$ ug. $\mathrm{kg}^{-1}$ dose range. However, other parameters were found to be constant and, in addition, the manner of clearance variation /decreas. ing when dose increased from 30 to $50 \mathrm{ug} \cdot \mathrm{kg}^{-1}$ and aftervards increasing when dose increased from 50 to $100 \mathrm{ug} \cdot \mathrm{kg}^{-1 /}$ suggests that there may be a problem of interindividual variation rather than of dose-related differences in the parameters. The $t_{1 / 2 \alpha}$ and $t_{1 ; 2 \beta}$ values of $\mathrm{EE}_{2}$ obtained in the present study were lower than those previously reported in rabbits after a 100 ug. $\mathrm{kg}^{-1}$ dose $\left(14.4\right.$ and $103.8 \mathrm{~min}^{14} 30$ and $\left.180 \mathrm{~min}^{15}\right)$. The $\mathrm{Cl}$ obtained in this study for the $100 \mu \mathrm{g} \cdot \mathrm{kg}^{-1} \mathrm{EE}_{2}$ group (116.3 $\left.\mathrm{ml} \cdot \mathrm{min}^{-1} \cdot \mathrm{kg}^{-1}\right)$ is higher than the values reported by Back et al. ${ }^{14}\left(28.3 \mathrm{ml} . \mathrm{min}^{-1} \cdot \mathrm{kg}^{-1}\right)$ and Dustcrberg et al. ${ }^{15}\left(37 \mathrm{ml}\right.$. $\left.\mathrm{min}^{-1} . \mathrm{kg}^{-1}\right)$ in the same aniinal species. The central volume of distribution reported by Dusterberg et al. ${ }^{15}\left(2.31 . \mathrm{kg}^{-1}\right)$ is comparable to that obtained in this study i $1.21 . \mathrm{kg}^{-1} 1$, but the noncompartmental terminal volume of distribution 119.1 $1 . \mathrm{kg}^{-1} !$ is higher than that reported by Back et al. ${ }^{1 /} 14.8$ $1 . \mathrm{kg}^{-1}$ !. We think that the discrepancies found in these data are due to difierences in the time of plasma sam. pling selected to give a basis for interpreting the phar. macokinetic behaviour of $E E_{2}$ in the three studies Back et al. " with eleven sample times and last time at 480 mrnutes. Dusterberg at al. ${ }^{15}$ with eight sample tumes and last time at 600 minutes and this paper with eighteen sample times and last time at $1+40$ minutesl.

As pointed out by Goldzieher in 1994, ' there is a wide variation in the pharmacokinetics of $E E_{2}$ re. ported by the different authors probably due to the difficulties in measuring plasma $E E_{2}$ levels, and also to the limitations in sampling frequency and kinetic treatment. We have solved the problem of interterences in quantification by using a specific HPLC-EC method. The effect of the sampling times is shown above by comparing data obtained with the same kinetic treatment. Furthermore, our study proves the influence of the kinetic treatment on the parameters $\lambda / \beta, V_{s s}$ and $V_{2}$. In our opinion, the pharmacokinetics of $E E_{2}$ after i.v. administration fits a twocompartment open model, and enteroheparic recircu. lation cannot be correctly quantified with the data obtained in this study. Further studies, such as using larger doses, cannulating the bile duct and so on. which would allow for this quantification, are needed.

\section{References}

1. Masterson BI. Oral contraceptive agents: current status. Am I Surg 1988; 155:619-27.

2. Godsland IF, Cook D, Wynn V. Clinical and metabolic considerations of long-term oral contraceptive use. Am i Obstet Gynecol 1992; 166:1955-63.

3. Goldzieher $\Gamma W$. Pharmacokinetics and metaholism of ethinyl estrogens. In: Goldzieher IW, Fotherby K. eds. Pharmacology of the contraceptive steroids New York:Raven Press, 1994:127-j1.

4. Hümpel M, Nieuweboer B, Wendt $H$, Speck U. Invest:gations of pharmacokinetics of ethinvluestradinl to ipe citic consideration of a possible irre: pass ctrces in women. Contraception 19:-7:19:2121: :2

4. Kuhnz W, Louton T. Back DI. Machacils k. R.r.jum. munolugical analyses of ethunviestr.adoul in human e. rum. Arzaeim-Forsch Drug Res 194; +1 1 $16-21$

6. Dibbelt L. Knuppen R, Jurting G. Humann S. Klimpung CO, Parikkı-Olexih H. Group compurisun of crum ethinylestradiol, SHBG and CBG levels in 4.3 ivim:? 
using two low-dose combination oral contraceptives for three months. Contraception $1991 ; 43: 1-21$.

7. Fernández N, García П, Diez MI, Terán MT, Sierra M. Rapid high-periormance liquid chromatographic assay of ethynylnestradiol in rabbit plasma. I Chromatogr Biomed Afpl 1993;619:143-7.

8. Metzler C.M, $W$ siner DL. PCNONLIN user's guide, version 3.0. Statistical Consultants, Lexington, KY, 1989.

9. Dunne A. IANA: A new iterative polyexponential curve stripping program. Compur. Meth Prog Biomed 1985;20: 269-75.

10. Yamaoka K, Nakagawa T, Uno T. Application of Akaike's information criterion $(\mathrm{AIC})$ in the evaluation of linear pharmacokinetic equations. I Pharmacokinet Bjopharm 1978;6:165-75.

11. Gibaldi $M$, Perrier D. Multicompartment models. In: Pharmacokinetics. New York:Marcel Dekker, 1982:15111.

12. Yamioka K, Nakagawa T, Uno T. Statistical moments in pharmacokinetics. I Pharmacokinet Biupharm 1979;6:547-58.
13. Fotherby K, Akpoviroro I, Abdel-Rahman. HA et al. Pharmacokinetics of ethinyloestradiol in women fron different populations. Contraception 1981;23:487-97.

14. Back DI, Breckeridge AM, Cross KI, Orme ML'E, Thomas. $E$. An antibiotic interaction with ethinyloestradiol in the rat and rabbit. I Steroid Biochem 1982;16:407-13.

15. Düsterberg B, Kühne G, Tüuber U. Hali-lives in plasma and bioavailability of ethinylestradiol in laboratory animals. Arzneim-Forsch Drug Res 1986;36:1187-90.

16. Back DI, Breckeridge AM, Crawtord FE et al. An investigation of the pharmacokinetics of ethinylestradiol in women using radioimmunoassay. Contraception 1979; 20:263-73.

17. Orme ML'E, Back DJ. Factors affecting the enterohepatic circulation of oral contraceptive steroids. Am I Obstet Gynecol 1990;163:2146-52.

18. Zacur HA, Burkman RT, Kimball AW, Kwiterovich $P$, Bell WR. Existence of multiple peaks in plasma ethinyl estradiol and norethindrone after oral administration of a contraceptive pill. J Clin Endocrinol Metab 1992; 75: 1268-72. 